\title{
Metodologias facilitadoras na Educação Física: objetivando o desenvolvimento social e o autodomínio emocional
}

Facilitating methodologies in Physical Education: aiming social development and emotional self-domain

\author{
Alessandra Weiss Ferraz de Oliveira \\ Universidade Federal do Paraná, Brasil \\ alewfo@hotmail.com \\ Marcio José Kerkoski \\ Universidade Tecnológica Federal do Paraná, Brasil \\ marciok@utfpr.edu.br \\ Wanderley Marchi Júnior \\ Universidade Federal do Paraná, Brasil \\ wmarchijr@gmail.com \\ Ana Paula Cabral Bonin Maoski \\ Universidade Tecnológica Federal do Paraná, Brasil \\ bonin.anapaula@gmail.com \\ Gilmar Francisco Afonso \\ Universidade Tecnológica Federal do Paraná, Brasil \\ gildoxyz@hotmail.com
}

\section{Resumo:}

O uso de estratégias e o repertório de emoções aprendidas com o passar dos anos proporcionaram o amadurecimento emocional dos indivíduos em formação. Mas a estrutura mental tem sofrido mudanças, o alto nível de exigência escolar e profissional, a diminuição da prática esportiva e a menor convivência social têm desencadeado no adolescente danos decorrentes do estresse. Desse modo, a Educação Física escolar no período da adolescência pode ser fundamental para o amadurecimento das aptidões emocionais de empatia e autocontrole, responsáveis pelo desenvolvimento do autodomínio emocional. O objetivo desta pesquisa foi apresentar possíveis metodologias facilitadoras para a aprendizagem emocional, especificamente, para o desenvolvimento do autodomínio emocional e social, durante o processo de ensino-aprendizagem na Educação Física escolar. Nesta perspectiva, a presente pesquisa caracteriza-se como pesquisa bibliográfica. A análise envolveu as obras dos autores Brearley (2004) e Alzinaet al. (2009), que permitiram visualizar a aprendizagem emocional na prática docente. A partir das obras reconstruímos possibilidades que podem ser facilitadores na metodologia do professor de Educação Física escolar e, consequentemente, para a formação integral do aluno. Palavras-Chave: Educação Física escolar, Metodologias facilitadoras, Autodomínio emocional, Emoções, Ensinoaprendizagem.

\section{ABSTRACT:}

The use of strategies and the repertoire of emotions learned over the years provided emotional maturation of training individuals. But the mental structure has undergone changes, the high level of school and professional demands, the decrease in sports practice and the lower social life have triggered stress damage in adolescents. Thus, school Physical Education during adolescence can be fundamental for the maturation of the emotional skills of empathy and self-control, which are responsible for the development of emotional self-control. The aim of this research was to present possible facilitating methodologies for emotional learning, specifically for the development of emotional and social self-mastery, during the teaching-learning process at school Physical Education. In this perspective, the present research is characterized as bibliographic research. The analysis involved the works of the authors Brearley (2004) and Alzina et al. (2009), which allowed the visualization of emotional learning in teaching practice. From these works, we reconstruct possibilities that can be facilitators in the methodology for the school Physical Education teacher and, consequently, for the integral formation of the student.

KEYWORDS: School Physical Education, Facilitating methodologies, Emotional self-control.

\section{Recepción: 15 de septiembre de 2019 | Aprobación: 17 de mayo de 2020 | Publicación: 01 de junio de 2020}




\section{INTRODUÇÃo}

Desde a infância, o indivíduo aprende a modelar suas emoções de acordo com o código de conduta instaurado na sociedade, que se torna elemento constituinte da sua personalidade (Elias, 2011). A partir da relação interpessoal e intrapessoal entre a criançae o adulto, principalmente pais e professores, são interiorizadas as normas sociais que regem o comportamento(Goleman, 2007), ou seja, a instituição familiar e escolar têm um importante papel no desenvolvimento e no amadurecimento das emoções durante a aprendizagem e, consequentemente,na vida em sociedade (Brearley, 2004;Alzinaet al.,2009).

A capacidade para controlar os próprios instintos foi desenvolvida mediante um processo a longo prazo, os sujeitos precisaram experenciar, aprender com o meio e se expor a determinadas situações paradesenvolver ações conscientes e inconscientes durante oconvíviosocial (Elias \&Dunning, 1992). Esse processo ocorreu por intermédio da família e do ambiente escolar, no aperfeiçoamento das maneiras e do comportamento, resultando no aumento do repertório de emoções e, consequentemente, no amadurecimento emocional dos indivíduos, somado às vivências positivas eaos conflitos interpessoais solucionados na infância e na adolescência (Brearley, 2004; Goleman, 2007). Como afirmou Elias (1993, p. 2005)

A teia de relações sociais em que vive o indivíduo durante a fase da infância e juventude, que se imprime em sua personalidade em formação, tendo sua contrapartida na relação entre suas instâncias controladoras, o superego, o ego e os impulsos da libido. O equilíbrio resultante entre essas instâncias controladoras e as pulsões vai determinar como a pessoa se orienta em suas relações com outras, determina aquilo que chamamos de hábitos, complexos ou estrutura da personalidade.

Em uma perspectiva temporal, a estrutura mental tem sofrido mudanças devido a evolução das sociedades, alterando os padrões de controle, prática e consciência social (Elias, 2001). Na atualidade, é possível notar que as crianças e adolescentes vivem uma realidade propícia para a menor concentração em aula e menor contato social (Goleman, 2014), um dos motivos, é a ausência da instituição escolarno atendimentoàs necessidades educacionais de seus alunos, deixando de promover a sintonia necessária para o interesse e atenção na aprendizagem (Goleman\&Senge, 2015).

No que diz respeito ao aspecto emocional, concordamos com a seguinte citação "aprendemos mais quando temos alguma coisa que nos interessa e nos dá prazer quando nos empenhamos nela” (Goleman, 2007, p. 116), com o uso de estratégias para tornar as crianças e adolescentes conscientes de como devem aprender a maximizar a sua eficácia pessoal, transformando na sua "segunda" natureza, o professor pode colaborar para o envolvimento e motivação do aluno na tarefa (Brearley, 2004). O que corrobora com o conceito de habitus, por Elias (2017), aonde as características pessoais são incorporadas pelo meio social, resultando na "segunda pele" ou "saber social incorporado".

Diante do exposto, refletimos sobre a importância da prática docente intencional para a aprendizagem do adolescente, que vai além do conteúdo programático, com o aprimoramento das aulas a partir do perfil do alunoproporcionando o desafio ideal para cada idade e superando as emoçóes negativas que possam surgir durante a aprendizagem (Brearley, 2004). Afinal, as emoções negativas geram no aprendiz uma preocupação exacerbada capaz de provocar distração e diminuição na concentração, prejudicando a aprendizagem significativa, pois "quando somos emocionalmente muito afetados por um sentimento negativo, com frequência também não conseguimos processar uma informação" (Sluyter\&Salovey, 1999, p. 56).

De uma maneira geral, na adolescência, o alto nível de exigência escolar e profissional, a diminuição da prática esportiva e a menor convivência social têm desencadeado danos decorrentes do estresse. Em outras palavras, as alterações fisiológicas, próprias dessa fase da vida, acrescidas da influência do meio externo tem sido preditores de comportamentos típicos da adolescência, podendo ocorrerem alguns casosa predisposição para comportamentos de risco e a queda no desempenho escolar. Culminando para 
a vulnerabilidade daqueles sujeitos que no período da infância apresentaram dificuldades para adquirir estratégias ou administrar as tensões (Tricoli, 2010).

Considerando o contexto escolar, esse jovem em formação ainda é compreendido apenas como aluno e pouco como sujeito, levando em conta suas demandas e expectativas (Oliveira\&Kerkoski, 2017). Como afirmou Leão, Dayrell\& Reis (2011), é fundamental o professor fazer uso de práticas pedagógicas intencionais e voltadas às necessidades desta idade, percebendo o adolescente e reconhecendo as dimensóes que norteiam esse período da vida.

Mediante o exposto, a Educação Física escolar no período da adolescência pode proporcionar ao aluno o contato com as mais diversas emoções, que precisam ser compreendidas e controladas,colaborandopara o amadurecimento das aptidóes emocionais de empatia e autocontrole responsáveis pelo desenvolvimento do autodomínio emocional. Segundo Elias (1998) o autodomínio pelo olhar sociológico, pode ser compreendido como o entrelaçamento entre as emoções, o ambiente e as relações sociais dos sujeitos envolvidos em configurações específicas. Na perspectiva da neurociência, envolve a consciência dos estados interiores e a gestão desses estados (Goleman, 2012).No entrelaçar desses conceitos, percebemos que durante o ensino do esporte e da atividade física o professorpode mediar a aprendizagem emocional do discente,com o uso de práticas voltadas à consciência de como se sente e à identificaçãodas possíveis barreiras emocionais, fortalecendo o processo de ensino-aprendizagem (Kerkoski, 2009).

Contudo, torna-se necessário instrumentalizar o professor acerca desta temática, como objetivo desta pesquisa, apresentaremosas metodologias facilitadoras para a aprendizagem emocional, especificamente, para o desenvolvimento do autodomínio emocional e social, durante o processo de ensino-aprendizagem na Educação Física escolar. A intenção é colaborar para o meio acadêmico e principalmente para a disseminação de procedimentos metodológicos capazes de auxiliar professores de Educação Física durante a prática docente e, consequentemente, durante a formação integraldo aluno.

\section{Metodologia}

Como procedimento metodológico adotado, optamos por uma pesquisa do tipo pesquisa bibliográfica. De acordo com Prodanov e Freitas (2013) é a pesquisa que depende de material já publicado, utilizando como referência as fases da pesquisa bibliográfica de Lakatos \& Marconi (2003), realizamos a escolha do tema, identificamos os autores que abordam a temática, compilamos as obras e realizamos a análise e interpretação. Para a análise das obras encontradas, usamos como alicerce a Teoria do Processo Civilizador de Norbert Elias (1993; 2011) e a Teoria da Inteligência Emocional de Daniel Goleman (2007; 2012).

A fim de atingir o objetivo proposto desta investigação, apresentar as metodologias facilitadoras para o desenvolvimento social e para o autodomínio emocional de alunos adolescentes, foram analisadas as obras dos autores Brearley (2004) e Alzinaet al. (2009), pois permitem visualizar a aprendizagem emocional na prática docente. A partir das obras reconstruímos possíveis procedimentos metodológicos para as aulas de Educação Física escolar.

O livro "A inteligência emocional na sala de aula: estratégias de aprendizado criativo para alunos entre 11 e 18 anos de idade" do autor Brearley (2004), foi escolhido por abordar com profundidade as estratégias pedagógicas durante o trabalho com a inteligência emocionalno processo de ensino-aprendizagem, implementando ações para o "Programa de Aprendizado Mágico" direcionadas ao currículo escolar. Além disso, utiliza como alicerce autores renomados na área de estudo, como Abraham Maslow, Carl Rogers, Howard Gardner, entre outros. Já o livro "Atividades para o desenvolvimento da inteligência emocional nas crianças"de Alzinaet al. (2009), enfatiza sugestões de atividades práticas para o desenvolvimento das competências emocionais, como: a consciência emocional, adequação emocional, autonomia, habilidades socioemocionais e habilidades para a vida e o bem-estar. $\mathrm{O}$ que corroborapara a compreensão da ação educativa na formação emocional de crianças, com atividades e intervenções específicas. 
Deste modo, entendemos que realizar o diálogo entre os autores permite apresentarmos as possibilidades metodológicas para a prática do professor de Educação Física que busca ensinar além da técnica. Existem outras abordagens que podem ser usadas para o desenvolvimento emocional, como por exemplo, a obra de Daniel Goleman (2007;2012), apresenta as "Emoções de Sucesso" com exemplos práticos da vida cotidiana para o aprimoramentodas aptidões de autoconsciência, empatia, reflexão, autoajuste, motivação, habilidades sociais e criatividade.

Reiteramos, os autores utilizados nesta investigação trazem um arcabouço teórico sobre o desenvolvimento da inteligência emocional na sala de aula, com programas e propostas de ensino independente da disciplina, faremos a seguir uma reconstrução para novas possibilidades direcionadas à Educação Física escolar.

Algumas pesquisas abordam as emoções na Educação Física, como por exemplo, na obra de Oliveira, Kerkoski\& Afonso (2019) é possível visualizar as metodologias de ensino-aprendizagem que proporcionam o desenvolvimento do autodomínio emocional em diversas áreas do saber. Em outras perspectiva, o trabalho de Castellani (2011) retrata a relação entre o pesquisador e clube de futebol pelo viés da psicologia social. Contudo, em uma breve busca utilizando a palavra chave "emoções na Educação Física escolar" no Portal de Periódicos da CAPES, percebemos a ausência de investigações sobre as emoções na metodologia do professore o seu uso na práticada sala de aula. Dos 333 artigos encontrados, a partir da análise dos títulos e resumos, os assuntos recorrentes foram: a formação de professores (Simões, Custódio \& Rezende Júnior, 2016; Pereira, Martiny \& Silva, 2018), esporte e valores (Raposo, 2012; Dos Santos, 2014), doença crônica e afeto (Rochaet al., 2012), motivação para a prática (Martinelli \& Aguena, 2011; Colaço et al., 2012) epsicomotricidade (Aquino et al., 2012; Rezende, Moreira \& Torres, 2014). Os artigos excluídos envolviam as seguintes temáticas: deficiência, currículo escolar, exclusão escolar, diversidade sexual, estética, educação infantil e outras áreas de estudo (matemática, português, arte, etc.).

\section{Resultados E Discussóes}

Diante das obras dos autores Brearley (2004) e Alzinaet al. (2009), estabelecemos o contato com possíveis metodologias para o desenvolvimento da Inteligência Emocional na sala de aula. Sobretudo, entendemos que a aprendizagem emocional demanda tempo e aperfeiçoamento, apenas emitir um comentário ou dar uma bronca no momento de conflito é insuficiente, pois toda aprendizagem requer repetição, insistência e treinamento diário (Alzinaet al., 2009), com atividades que permitam atingir as competências emocionais necessárias para o amadurecimento das aptidões relacionadas ao autodomínio emocional.

Deste modo, compreendemos o significado de competência emocionalpela definição de Alzinaet al. (2009), como a ação de colocar em prática conhecimentos, capacidades, habilidades e atitudes, fundamentais para uma adequada compreensão e expressão de emoções. Na obra "Atividades para o desenvolvimento da inteligência emocional nas crianças”, encontramos cinco blocos de competências, relacionadas: a consciência emocional, adequação emocional, autonomia emocional, habilidades socioemocionais e habilidades para a vida e o bem-estar emocional. Já no livro "Inteligência Emocional na sala de aula: estratégias de aprendizado criativo para alunos entre 11 e 18 anos de idade", identificamos cinco emoções de sucesso mencionada por Brearley (2004): autoconsciência, ambição, otimismo, empatia e integridade.

Os autores supracitados, esclarecem a importância dos pais e professores durante o desenvolvimento das competências emocionais para a vida, como qualquer outro processo de aprendizagem, são difíceis de se desenvolver, demanda esforços, treino e tempo, ou seja, é necessário estar disposto para investir e propiciar a devida atenção(Alzinaet al., 2009). A partir das competências mencionadas anteriormente, buscamos identificar as atividades relacionadas às aptidões emocionais de empatia e autocontrole, adaptando novas possibilidades no trabalho prático do professor.

Iniciaremos pela consciência emocional, entendida como "a capacidade de perceber, identificar e dar nomes aos sentimentos e emoções” próprios e das demais pessoas, expresso de maneira verbal ou não verbal, é 
a competência fundamental para que existam todas as demais (Alzinaet al., 2009, p. 10). Complementando, Madureira (2006) afirma que a consciência emocional se encontra intimamente relacionada ao autocontrole, pois o sujeito aprende a ouvir seus próprios sentimentos, ser coerente e sincero consigo mesmo, identificando suas emoções e do próximo.

Para desenvolver a consciência emocional podemos utilizar meios da Educação Emocional, aprendendo quando, onde e como expressar os próprios sentimentos, tomando consciência da influência nas outras pessoas e se responsabilizando pelas consequências desses sentimentos (Rêgo\& Rocha, 2009). É possível que seja desenvolvida através de jogos e perguntas, desde que seja estimulada a "consciência de como se sentem", algumas questóes provocativas que podem ser utilizadas, desde que tenha pertinência com a atividade programada: "como você se sente? O que tem vontade de fazer? Como acha que o outro se sente? O que você acha que ele tem vontade de fazer?” (Alzinaet al., 2009, p. 11), ou utilizando a abordagem de Brearley (2004) para a autoconsciência, o professor pode se questionar: “quais são as emoções de sucesso?” e como será a qualidade utilizada para o seu alcance, os costumes, atitudes e crenças de realização.

A partir da obra de Alzinaet al. (2009, p. 12 - 57) e Brearley (2004, p. 116), reconstruímos possibilidades que podem ser facilitadores na metodologia do professor de Educação Física para o desenvolvimento da consciência emocional, dentro e fora da sala de aula, com o enfoque para as aptidões emocionais de empatia e autocontrole.

É o que apresentamos no quadro, a seguir.

QUADRO 1

Atividades para a consciência emocional

\begin{tabular}{|c|c|c|c|}
\hline Descriçãa & Questões & Objetivo & Aptidão emocional \\
\hline 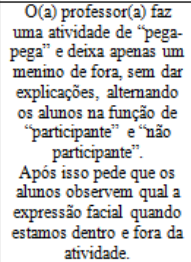 & $\begin{array}{l}\text { Como você se sentiu } \\
\text { ao brimcar junto com } \\
\text { os outros? } \\
\text { Como você se sentiu } \\
\text { ao não brimcar? } \\
\text { O que você faria para } \\
\text { ajudar aquele que } \\
\text { estava sozinho fora da } \\
\text { brincadeira?" }\end{array}$ & $\begin{array}{c}\text { Reconhecer e } \\
\text { identificar as emoçōes } \\
\text { das outras pessoas. }\end{array}$ & Empatia \\
\hline $\begin{array}{l}\text { O(a) professor(a) dispõe } \\
\text { para os alunos alguns } \\
\text { desenhos de expressões } \\
\text { faciais e pede para que } \\
\text { escolham aquela que } \\
\text { representa o seu } \\
\text { sentimento no inicio da } \\
\text { aula. Após o término da } \\
\text { aula, pede novamente } \\
\text { que escolham aquela que } \\
\text { representa o sentimento } \\
\text { naquele momento e } \\
\text { algumas questões para } \\
\text { serem trabalhadas em } \\
\text { grupo. } \\
\text { grupo. }\end{array}$ & $\begin{array}{c}\text { A emoção escolhida é } \\
\text { a mesma de seus } \\
\text { colegas, no inicio eno } \\
\text { fmal da tarefa? } \\
\text { Há alguma emoção } \\
\text { diferente das demais } \\
\text { no grupo? } \\
\text { Se sim, compreende } \\
\text { por que o colega sente } \\
\text { diferente?" }\end{array}$ & $\begin{array}{l}\text { Aceitar que nem todos } \\
\text { sentem a realidade da } \\
\text { mesma maneira. }\end{array}$ & Empatia \\
\hline $\begin{array}{l}\text { Após uma atividade } \\
\text { competitiva, por } \\
\text { exemplo, uma corrida de } \\
100 \text { metros valendo } \\
\text { medalah ou um tomeio } \\
\text { de voleibol. Pedir para os } \\
\text { alunos responderem } \\
\text { algumas questôes. }\end{array}$ & $\begin{array}{l}\text { Qual emoção você } \\
\text { sentiu no inicio da } \\
\text { partida? } \\
\text { Qual emoção você } \\
\text { sentiu durante? } \\
\text { Qual emoção você } \\
\text { sentiu no fmal da } \\
\text { partida? }\end{array}$ & $\begin{array}{c}\text { Reconhecer as } \\
\text { próprias emoçōes. }\end{array}$ & Autocontrole \\
\hline 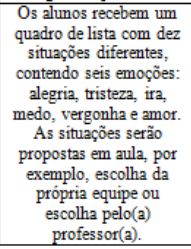 & $\begin{array}{c}\text { Como você se sentiu } \\
\text { ao escolher a própria } \\
\text { equipe? } \\
\text { Como vocế se sentiu } \\
\text { ao não escolher a } \\
\text { equipe? }\end{array}$ & $\begin{array}{c}\text { Relacionar emoçöes } \\
\text { com os } \\
\text { acontecimentos em } \\
\text { aula }\end{array}$ & Autocontrole \\
\hline
\end{tabular}

FONTE: Adaptação da obra de Brearley (2004) e da obra de Alzinaet al. (2009)

Na sequência, os autores Alzinaet al. (2009), descrevem a segunda competência, chamada de adequação emocional, que pode ser compreendida conforme o significado, encontrado no dicionário, da palavra "adequar": "amoldar, acomodar, proporcionar, igualar, acomodar-se, conformar, adequamos" (Bueno, 2007, p. 26). Essa competência envolve a condição de saber "adequar as emoções e esperar o momento oportuno para falar", ou seja, acomodar as emoções para agir de maneira assertiva nas situações cotidianas. Além disso, podemos entender como a capacidade de autogerar emoções positivas, após termos consciência das emoções 
que desencadeiam o estado de humor positivo ou negativo, atuando de maneira estratégica nas situações críticas e de conflitos (Alzinaet al., 2009). Segundo Brearley (2004, p. 104), no "Programa de Aprendizado Mágico", a emoção correspondente seria o "otimismo", como a "capacidade de vermos comentários feitos com um retorno que nos ajuda a aprender e a ter controle", assim controlar a ira pode ser uma estratégia para evitar ações violentas (Alzinaet al., 2009, p. 58 - 59). Para isso precisamos aprender a lidar com a ira, com muito esforço, tempo e treinamento.

A adequação emocional é essencial quando se interage com outras pessoas, como acontece com os colegas de classe. É essencial saber escutar, não se precipitar, formular perguntas, aceitar silêncios, introduzir estratégias de melhoria do clima emocional, etc. (Alzinaet al., 2009, p. 59).

Nesse sentido, a partir dos autores reelaboramos algumas atividades para a aprendizagem da adequação emocional/otimismo, com o enfoque no autodomínio. É o que descrevemos no quadro, a seguir.

\section{QUADRO 2}

Atividades para a adequação emocional/otimismo

\begin{tabular}{|c|c|c|c|}
\hline Descrição & Questões & Objetivo & Aptidão emocional \\
\hline $\begin{array}{l}\text { Em uma cartolina o(a) } \\
\text { professor(a) desenha a } \\
\text { imagem do semáforo, na } \\
\text { sequência das cores } \\
\text { vermelha, amarela e } \\
\text { verde. Junto com os } \\
\text { alunos define o } \\
\text { significado de cada } \\
\text { cor,por } \\
\text { exemplo:"vermelho" } \\
\text { pare, "amarelo" respire } \\
\text { fundo e no "verde" } \\
\text { explique o problema e } \\
\text { como se sente. }\end{array}$ & $\begin{array}{c}\text { Pense na luz vermelha } \\
\text { e pare. Não grite, não } \\
\text { insulte, nem agida, } \\
\text { reflita. } \\
\text { Pense na luz amarela } \\
\text { e respire fundo até } \\
\text { que possa pensar com } \\
\text { clareza.Pense na luz } \\
\text { verde e diga aos } \\
\text { demais os problemas, } \\
\text { como se sente para } \\
\text { tentar encontrar uma } \\
\text { solução. }\end{array}$ & $\begin{array}{c}\text { Adquirir uma estratégia } \\
\text { para adequar as } \\
\text { emoções }\end{array}$ & Autocontrole \\
\hline $\begin{array}{l}\text { Após uma atividade } \\
\text { intensa, o(a) professor(a) } \\
\text { acomoda os alunos em } \\
\text { alguns colchonetes e } \\
\text { pede para que fechem os } \\
\text { olhos e "inspire" e } \\
\text { "expire" tranquilamente, } \\
\text { orientando para que } \\
\text { sintam as partes do } \\
\text { corpo: cabeça, pescoço e } \\
\text { assim por diante. } \\
\text { Dissolvendo as tensões } \\
\text { de maneira a buscar o } \\
\text { relaxamento corporal } \\
\text { completo. }\end{array}$ & $\begin{array}{c}\text { Durante a atividade } \\
\text { responda: qual a parte } \\
\text { do seu corpo está mais } \\
\text { tensa? } \\
\text { Perceba por que } \\
\text { algumas partes do } \\
\text { corpo estão mais } \\
\text { tensas? }\end{array}$ & $\begin{array}{l}\text { Aprender formas de } \\
\text { relaxamento para a } \\
\text { diminuição de tensões. }\end{array}$ & Autocontrole \\
\hline
\end{tabular}

FONTE: Adaptação da obra de Brearley (2004) e da obra de Alzinaet al. (2009)

Como nas demais competências, a autonomia emocional encontra-se associada ao autodomínio, pois é "a capacidade para analisar criticamente as normas sociais, a capacidade para buscar ajuda e recursos, a capacidade para avaliar” (Alzinaet al., 2009, p. 88). De maneira que o sujeito seja capaz de expressar como se sente, adotando valores positivos sobre si mesmo, na busca de ajuda quando necessário. Essa competência permite também desenvolver a empatia, já que implica em estar no meio como agente social, aderindo os 
valores de responsabilidade com os demais e adotando habilidades sociais positivas. Em síntese poderíamos afirmar, é a condição para que o indivíduo se perceba como integrante do meio social, para além da percepção de suas emoções, recebendo feedbacks positivos ou negativos de outras pessoas, desde o nascimento até os doze anos de idade, e assim moldando a sua personalidade (Alzinaet al., 2009). Na abordagem de Brearley (2004, p. 115), estaria associado a emoção de "empatia", no "desenvolver processos de auto-revisão" sendo "solidário com o sucesso" por meio do otimismo e da "confiança vinda de outras pessoas".

Do mesmo modo, citamos algumas atividades elaboradas a partir da obra de Brearley (2004) e Alzina et al. (2009), com o enfoque pedagógico. É o que expomos no quadro, a seguir.

QUADRO 3

Atividades para a autonomia emocional/empatia

\begin{tabular}{|c|c|c|c|}
\hline Descrição & Questões & Objetivo & Aptidão emocional \\
\hline $\begin{array}{l}\mathrm{O}(\mathrm{a}) \text { professor(a) entrega } \\
\text { para seus alunos uma } \\
\text { folha contendo um } \\
\text { quadro de "aspectos } \\
\text { positivos" e "aspectos } \\
\text { negativos". }\end{array}$ & $\begin{array}{l}\text { Como você se sentiu } \\
\text { ao ler seus pontos } \\
\text { positivos e negativos? }\end{array}$ & $\begin{array}{l}\text { Promover a construção } \\
\text { da identidade. }\end{array}$ & Autocontrole \\
\hline $\begin{array}{c}\text { Essa folha deverá passar } \\
\text { por todos da classe e, } \\
\text { posteriormente, por seus } \\
\text { familiares. }\end{array}$ & $\begin{array}{c}\text { Foi importante saber a } \\
\text { opinião de outras } \\
\text { pessoas? } \\
\text { Alguma surpresa ao } \\
\text { ler a devolutiva das } \\
\text { pessoas? }\end{array}$ & & \\
\hline $\begin{array}{l}\text { No final do primeiro } \\
\text { semestre, o(a) } \\
\text { professor(a) entrega para } \\
\text { seus alunos uma folha } \\
\text { contendo as seguintes } \\
\text { questões: "aprendi } \\
\text { sozinho" e "aprendi com } \\
\text { o grupo". } \\
\text { No final do ano, o } \\
\text { professor retoma a } \\
\text { atividade novamente } \\
\text { propondo a comparativa. }\end{array}$ & $\begin{array}{c}\text { Você gosta de como } \\
\text { aprendeu? } \\
\text { Você gosta de } \\
\text { aprender com o } \\
\text { grupo? } \\
\text { O que você mudaria } \\
\text { durante o processo? }\end{array}$ & Ter consciência de si. & Autocontrole \\
\hline
\end{tabular}

FONTE: Adaptação da obra de Brearley (2004) e da obra de Alzina et al. (2009)

De maneira sucinta iremos apresentar alguns conceitos e atividades referente as últimas competências emocionais mencionadas na obra de Alzina et al. (2009): habilidades socioemocionais e habilidades para a vida e o bem-estar emocional, no olhar de Brearley (2004) seriam as emoções de "ambição e motivação" e "integridade". De acordo com os autores Alzina et al. (2009), as habilidades socioemocionais são atitudes que favorecem as relações com os demais, algumas delas são: assertividade, empatia, saber escutar, definir um problema, avaliar soluções e negociação. Bem como, as habilidades para a vida e o bem-estar emocional são recursos para a superação de acontecimentos diários e imprevistos, adotando uma atitude positiva. $\mathrm{Na}$ perspectiva de Brearley (2004, p. 99), seria a capacidade de "estabelecer objetivos pessoais na escola e na vida" e esses objetivos devem motivar e estar de acordo com o senso de integridade. Assim, entendemos que essas competências também podem colaborar para o desenvolvimento do autodomínio emocional, pois envolvem a aprendizagem das aptidóes emocionais de empatia e autocontrole, como veremos no quadro a seguir. 


\section{QUADRO 4}

Atividades para habilidades socioemocionais e habilidades para a vida e o bem-estar emocional/ambição, motivação e integridade

\begin{tabular}{|c|c|c|c|}
\hline Descrição & Questões & Objetivo & Aptidão emocional \\
\hline $\begin{array}{l}\text { No início da aula o(a) } \\
\text { professor(a) propõe a } \\
\text { seguinte tarefa: nas } \\
\text { próximas duas aulas as } \\
\text { atividades e a } \\
\text { comunicação entre vocês } \\
\text { acontecerão através de } \\
\text { mímica, não sendo } \\
\text { permitido falar, terão que } \\
\text { se expressar. }\end{array}$ & $\begin{array}{c}\text { Quais foram as } \\
\text { dificuldades? } \\
\text { Consegui expressar o } \\
\text { que gostaria de falar? } \\
\text { Entendi a expressão } \\
\text { corporal do } \\
\text { professor(a) e dos } \\
\text { colegas? }\end{array}$ & $\begin{array}{c}\text { Reconhecer a } \\
\text { importância da } \\
\text { comunicação não } \\
\text { verbal a partir da } \\
\text { expressão corporal. }\end{array}$ & Autocontrole e empatia \\
\hline $\begin{array}{l}\text { Após uma partida com a } \\
\text { equipe rival, ou após um } \\
\text { campeonato. Entregar } \\
\text { para os alunos desenhos } \\
\text { de expressões faciais e } \\
\text { pedir para que circulem } \\
\text { aquela que representa a } \\
\text { emoção percebida } \\
\text { naquele momento } \\
\text { (assustado, irritado, } \\
\text { choroso, brincalhão, } \\
\text { contente, entre outros). } \\
\text { Após isso pedir que, em } \\
\text { grupo, percebam se as } \\
\text { expressões faciais } \\
\text { circuladas são comuns a } \\
\text { todos. }\end{array}$ & $\begin{array}{l}\text { Como se sentiu ao ver } \\
\text { que os colegas } \\
\text { marcaram itens } \\
\text { diferentes do seu? } \\
\text { Como você se sentiria } \\
\text { se estivesse na equipe } \\
\text { adversánia? } \\
\text { O que pode ser feito } \\
\text { para você se sentir } \\
\text { diferente? }\end{array}$ & $\begin{array}{l}\text { Compreender que } \\
\text { existem diferentes } \\
\text { maneiras de ver as } \\
\text { coisas e aceitar o } \\
\text { ponto de vista dos } \\
\text { outros. }\end{array}$ & Autocontrole e empatia \\
\hline
\end{tabular}

FONTE: Adaptação da obra de Brearley (2004) e da obra de Alzina et al. (2009)

Como apresentado, existem várias abordagens para a aprendizagem emocional, a proposta de Brearley (2004, p. 14-17), diferentemente de Alzina et al. (2009), trabalha com o enfoque no adolescente. Portanto, é relevante para esta investigação mencionarmos o "Programa de Aprendizado Mágico", composto pela alfabetização emocional e aprendizado emocional, "com o objetivo de dar a todos os alunos um conjunto de ferramentas emocionais para o sucesso", concentrando a proposta educativa no processo e não no conteúdo. Durante a alfabetização emocional os alunos aprendem a descrever e compreender as próprias emoções e do próximo; no aprendizado emocional o aluno aprende como usar essas emoções previamente identificadas, ou seja, como responder ao ambiente. O processo de aprendizagem contempla: "sistema de representações", que são os nossos sentidos; "orientação": como utilizamos nossos sentidos no momento de falar e de se expressar; "ligação": conhecer e utilizar mais de um sentido durante a aprendizagem; e "efeito": o aluno compreende como adquiriu o conhecimento.

Segundo o autor, os alunos assimilam as informações de forma diferentes, alguns utilizam a audição, outros a visão ou a cinestesia. No transcorrer, após o sistema de representações receber as primeiras informações do ambiente, responde ou reage a partir de uma orientação que pode influenciar o bom relacionamento, "desencadeando a participação de outros sentidos e experiências que contribuem para novas aprendizagens” (Brearley, 2004, p. 24). 
Nesse sentido, para atingir a proposta do programa se torna necessário que os professores adquiram determinadas atitudes, como relembrar o conteúdo aprendido anteriormente e "de como eles se sentiram no aprendizado, recordar o máximo as memórias positivas”. Além disso, é possível, promover a partir de uma aula de relaxamento a retomada desses conteúdos e sentimentos, como também pedir para que os alunos percebam seus movimentos e como se sentem durante a realização da tarefa (Brearley, 2004, p. 31).

\section{Conclusão}

A partir das obras de Brearley (2004) e de Alzina et al. (2009), obtivemos acesso a possíveis métodos e atividades para o desenvolvimento emocional de alunos em processo de ensino-aprendizagem, nas diferentes faixas etárias. Entretanto, as obras pesquisadas articulam a inteligência emocional e as possibilidades de ensino, sem especificarem uma determinada área do saber. Em vista disso, reconstruímos possibilidades que podem ser facilitadores na metodologia do professor de Educação Física escolar que trabalha com o adolescente, devido a decorrência das demandas sociais atuaisdesta fase da vida.

Com base nas reflexões apresentadas, ao que concerne a importância do desenvolvimento do autodomínio emocional no processo de ensino-aprendizagem, evidenciamos que a Educação Física pode ser fundamental para o amadurecimento das aptidões emocionais de empatia e autocontrole, pois proporciona ao aluno o contato com as mais diversas emoções, que precisam ser compreendidas e controladas. Contudo, é necessário instrumentalizar o professor, para que tenha condições de proporcionar ao discente a consciência de como se sente, identificando as possíveis barreiras emocionais e fortalecendo assim o processo de ensinoaprendizagem.

Diante das obras analisadas, verificamos que algumas atitudes do professor e questóes problematizadoras sobre as emoções, durante ou após as atividades, podem colaborar para que o aluno compreenda como se sente, e também, como os outros costumam se sentir no grupo. Portanto, é fundamental construir objetivos e fins alinhados a intenção de desenvolver as aptidões emocionais.

Ademais, compreendemos que o professor de Educação Física pode utilizar metodologias que facilitem o trabalho com as emoções durante as aulas, desde que, elaboreatividades que permitam atingir as competências emocionais necessárias para o amadurecimento das aptidões relacionadas ao autodomínio emocional, e adquira determinadas atitudes intencionais com o objetivo de permitir um espaço de diálogo sobre as emoções em aula.

\section{REFERÊNCIAS}

Alzina, R. B., Escoda, N. P.,Bonilla, M. C.,Cassà, È. L., \&Guiu, G. F.\&Soler, M. O. (2009). Atividades para o desenvolvimento da inteligência emocional nas crianças. Barcelona: Ciranda Cultural.

Aquino, M., Browne, R., Sales, M., \& Dantas, R. A. (2012). A psicomotricidade como ferramenta da educação física na educação infantil. Revista Monografia Ambientais, v. 8, n 8, p. 1775-1786. Disponível em:<file://C:/Users/ alewf/Downloads/6186-27350-2-PB.pdf>. Acesso em 12 de setembro de 2020.

Brearley, M. (2004).Inteligência Emocional na sala de aula: estratégias de aprendizagem criativas para alunos entre 11 e 18 anos de idade. São Paulo: Madras.

Bueno, S. (2007).Minidicionário da língua portuguesa, 2 ed. São Paulo: FTD.

Castellani, R. M. (2011). Os [des]caminhos de um pesquisador do futebol brasileiro. Educación Físicay Ciencia, v. 13, n. 0 SE-Artículos. Disponível em: <https://www.efyc.fahce.unlp.edu.ar/article/view/EFyCv13a05>;. Acesso em 12 de setembro de 2020.

Colaço, C., Rosado, A., Ferreira, V., Gil, Rosimeiri\& Gil, R. (2012). Motivação para a Prática Desportiva nos Alunos do Ensino Básico e Secundário: Influência do Género, Idade e Nível de Escolaridade. Motricidade, v. 8, n. 4, p. 
38-51. Revista Motricidade / Edições Desafio Singular. Disponível em: <http://revistas.rcaap.pt/motricidade/ article/view/1551>;. Acesso em: 12 de setembro 2020.

Dos santos, L. S. (2014). A obtenção e melhoria dos valores humanos por adolescentes de 14 a 17 anos, por meio do esporte, na modalidade basquetebol. / Obtainingandimprovementofhumanvalues for teenagers from 14 to 17 yearsoldthroughbasketball. Revista Brasileira de Futsal e Futebol, v. 6, n. 22, p. 304-311. Disponível em: <http://search.ebscohost.com/login.aspx?direct=true\&db=s3h\&AN=125142642\&lang=ptbr\&site=eho st-live >;. Acesso em: 11 de setembro de 2020.

Elias, N., \&Dunning, E.(1992). A busca da excitação. Lisboa: Difel.

Elias, N. (1993). O processo civilizador: formação do Estado e Civilização. Vol. 2. Rio de Janeiro: Zahar.

Elias, N. (1998). Sobre o tempo. Rio de Janeiro: Zahar.

Elias, N. (2001). A sociedade de corte: investigação sobre a sociologia da realeza e da aristocracia de corte. Rio de Janeiro: Zahar.

Elias, N. (2011). O processo civilizador: uma história dos costumes. Vol. 1.2 ed. Rio de Janeiro: Zahar.

Elias, N. (2017).Introdução à Sociologia. Lisboa: Edições 70.

Goleman, D. (2007). Inteligência Emocional: a teoria revolucionária que define o que é ser inteligente. 45. ed. Rio de Janeiro: Objetiva.

Goleman, D. (2012). O cérebro e a inteligência emocional: novas perspectivas. Rio de Janeiro: Objetiva.

Goleman, D. (2014).Foco: a atenção e seu papel fundamental para o sucesso. $1^{\mathrm{a}}$ ed. Rio de Janeiro: Objetiva.

Goleman, D., \&Senge, P. (2015). O foco triplo. $1^{\text {a }}$ ed. Rio de Janeiro: Objetiva.

Kerkoski, M. J. (2009). Prática Desportiva e Inteligência Emocional: estudo da influência do desporto na aquisiz̧ão de aptidóes e competências da inteligência emocional. 339 f.Tese (Doutorado em Estudo da Criança), Universidade do Minho, Portugal.

Lakatos, E. M., \&Marconi, M. A. (2003). Fundamentos de metodologia cientifica. $5^{\mathrm{a}}$ ed. São Paulo: Atlas.

Leão, G.,Dayrell, J. T., \& Reis, J. B. (2011).Juventude, projetos de vida e Ensino Médio. Educação e Sociedade. p. 1067 1084. Disponível em: <http://www.scielo.br/pdf/es/v32n117/v32n117a10.pdf >;. Recuperado em 14 de agosto de 2017.

Madureira, M. D. (2006).O fator emocional e o professor de Educação Física no início da carreira: é possível que a inteligência emocional seja um instrumento favorável a melhoria das relaçóes humanas no exercício profissional?Revista Mackenzie de Educação Física e Esporte.p. 83-92. Disponível em: < http://profissional.unive rsoef.com.br/container/gerenciador_de_arquivos/arquivos/338/fator-emocional.pdf $>$;. Recuperado em 29 de agosto de 2018.

Martinelli, S., \& Aguena, E. (2014). La motivaciónenestudiantes de enseñanza fundamental y lascreencias y actitudes de los padres. Revista de InvestigaciónenPsicologia, v. 14, p. 53. Disponível em:<file://C:/Users/alewf/ Downloads/2062-Texto\%20del\%20art\%C3\%ADculo-7389-1-10-20130412.pdf>. Acesso em 12 de setembro de 2020.

Oliveira, A. W. F. de.,\&Kerkoski, M. J. (2017). Autodomínio e a adolescência: estudo dos fatores que influenciam na aprendizagem. Primus Vitam. p. 1-10, 2017. Disponível em: <https://mackenzie.br/fileadmin/OLD/47/Grad uacao/CCH/primus\%20_vitam/primus_9/Alessandra_Weiss.pdf >;. Recuperado em 3 de julho de 2018.

Oliveira, A. W. F. de.,Kerkoski, M.,\&Afonso, G. (2019). Esporte educacional e os procedimentos metodológicos para o autodomínio emocional. Educación Física y Ciencia, v. 21, n. 2 SE-Artículos, 2019. Disponível em: <https:// www.efyc.fahce.unlp.edu.ar/article/view/EFyCe081 >;. Acesso em 12 de setembro de 2020.

Pereira, I. D. N., Martiny, L. E.,\&Silva, P. N. (2018). “A expectativa não é muito boa não. É de desespero mesmo!” O impacto emocional na prática pedagógica dos professores em formação inicial. Motrivivência, v. 30, n. 54, p. 194-209, 2018. Disponível em: <https://periodicos.ufsc.br/index.php/motrivivencia/article/view/2175-8042 .2018v30n54p194>.Acesso em: 12 de setembro de 2020.

Prodanov, C. C., \& Freitas, E. C. (2013). Metodologia do trabalho cientifico: métodos e técnicas da pesquisa e do trabalho acadêmico, 2ed, Novo Hamburgo: Feevale. 
Raposo, J. V. (2012). Num desporto com valores: Construir uma sociedade mais justa. Motricidade, v. 8, n. 2, p. 1-7, 2012. Revista Motricidade / Edições Desafio Singular. Disponível em: <http://revistas.rcaap.pt/motricidade/ar ticle/view/707>;. Acesso em: 12 de setembro de 2020.

Rêgo, C. C. A., \& Rocha, N. M. F. (2009).Avaliando a educação emocional: subsídios para um repensar da sala de aula.Ensaio: Aval. Pol. Públ. Educ.,Rio de Janeiro. v.17, n62. p. 135- 152. Disponível em: <www.scielo.br/pdf/ ensaio/v17n62/a07v1762/pdf>. Recuperado em 15 de dezembro de 2018.

Rezende, L. M. T. De.,Moreira, O. C., Torres, J. De O. (2014). Importância do trabalho psicomotor em aulas de educação física para pessoas com deficiência. RBPFEX - Revista Brasileira de Prescrição e Fisiologia do Exercício, v. 8, n. 47 SE-Artigos Científicos-Revisão. Disponível em: <http://www.rbpfex.com.br/index.php/rbpfex/arti cle/view/672>;. Acesso em 12 de setembro de 2020.

Rocha, A. M., Porto, H. L. S.,Inacio, M. B., Souza, E. H. E. E.,\& Tolentino, G. (2012). Positive and negative affects in youngpeoplewithchronicconditions in publicschoolsofthecityof Montes Claros/MG/Afetos positivos e negativos em jovens acometidos por condicoescronicas da rede pública estadual de ensino da cidade de Montes Claros/. Motricidade, v. 8, p. 1105-1112.Disponível em:<https://www.redalyc.org/pdf/2730/273023568141. pdf $>$;. Acesso em 12 de setembro de 2020.

Simões, B., Custódio, J.,\&Junior, M. (2016). Motivações de licenciandos para escolha da carreira de professor de Física.Revista Brasileira de Pesquisa em Educação em Ciências, vol. 16, n 1, p. 77-107. Disponível em:<https://www.researchgate.net/publication/340790294_Motivacoes_de_licenciandos_para_e scolha_da_carreira_de_professor_de_Fisica >;. Acesso em 11 de setembro de 2020.

Sluyter, D. J.,\&SAlovey, P. (1999).Inteligência emocional da criança: aplicaçôes na educação e no dia a dia. Rio de Janeiro: Campus.

Tricoli, V. A. C., (org). (2010).Stress na adolescência: problema e solução: a possibilidade de jovens estressados se tornarem adultos saudáveis. São Paulo: Cada do Psicólogo. 